\title{
Establishment and Characteristics of a Novel Mantle Cell Lymphoma-derived Cell Line and a Bendamustine-resistant Subline
}

\author{
TOMOKO TAKIMOTO-SHIMOMURA ${ }^{1}$, HISAO NAGOSHI ${ }^{1,2}$, SAORI MAEGAWA $^{1}$, \\ YUTO FUJIBAYASHI1, TAKU TSUKAMOTO ${ }^{1}$, YAYOI MATSUMURA-KIMOTO ${ }^{1}$, \\ YOSHIMI MIZUNO ${ }^{1}$, YOSHIAKI CHINEN ${ }^{1}$, SHINSUKE MIZUTANI ${ }^{1,3}$, YUJI SHIMURA ${ }^{1}$, \\ SHIGEO HORIIKE ${ }^{1}$, MASAFUMI TANIWAKI ${ }^{1}$, TSUTOMU KOBAYASHI ${ }^{1}$ and JUNYA KURODA ${ }^{1}$ \\ ${ }^{1}$ Division of Hematology and Oncology, Department of Medicine, \\ Kyoto Prefectural University of Medicine, Kyoto, Japan; \\ ${ }^{2}$ Department of Hematology and Oncology, Research Institute for Radiation Biology and Medicine, \\ Hiroshima University, Hiroshima, Japan; \\ ${ }^{3}$ The Walter and Eliza Hall Institute of Medical Research, Parkville, Australia
}

\begin{abstract}
Background/Aim: Bendamustine hydrochloride $(B H)$ is a key therapeutic agent for mantle cell lymphoma $(M C L)$, while the mechanism underlying BH-resistance has not been verified. Materials and Methods: We compared molecular/biological characteristics of a newly-generated $M C L$-derived cell line KPUM-YYI and its BH-resistant subline KPUM-YYIR. Results: The growth-inhibitory $I C_{50}$ for $B H$ was $20 \mu M$ in KPUM-YY1 cells, while cell proliferation was not inhibited by up to $60 \mu \mathrm{M} \mathrm{BH}$ in KPUM-YYIR cells. Compared to KPUM-YY1 cells, gene expression profiling in KPUM-YYIR cells revealed upregulation of 312 genes, including $A B C B 1$ encoding $P$-glycoprotein $(P$-gp $)$, and microsomal glutathione $S$-transferase 1 (MGST1). Addition of either a P-gp inhibitor or a GST inhibitor, at least partly, restored sensitivity to $B H$ in KPUM-YYIR cells. In addition, KPUM-YYIR cells showed cross-resistance against various anti-MCL chemotherapeutics. Conclusion: BH resistance is mediated by overlapping mechanisms with overexpression of $A B C B 1$ and MGST1, and is potentially accompanied by multidrug resistance in $M C L$.
\end{abstract}

This article is freely accessible online.

Correspondence to: Junya Kuroda, MD, Ph.D. Division of Hematology and Oncology, Department of Medicine, Kyoto Prefectural University of Medicine, 465 Kajii-cho, Kamigyo-ku, Kyoto, 602-8566, Japan. E-mail: junkuro@koto.kpu-m.ac.jp

Key Words: Mantle cell lymphoma, bendamustine, resistance, ABCB1, MGST1.
Mantle cell lymphoma (MCL) is one of the most difficultto-treat subtypes of non-Hodgkin's lymphoma (NHL), despite recent advances in therapeutic strategies, including immunochemotherapy incorporating rituximab (RIT) and genotoxic agents, ibrutinib, bortezomib (BTZ), or high-dose chemotherapy followed by autologous stem cell transplantation (1-4). Amongst various cytotoxic agents, bendamustine hydrochloride $(\mathrm{BH})$ is one of the most promising central drugs in the treatment for MCL. BH exerts an anti-lymphoma effect through complex and overlapping mechanisms, including induction of apoptosis via a DNAdamage stress response, inhibition of mitotic checkpoints, and induction of mitotic catastrophe $(5,6)$.

In a clinical setting, $\mathrm{BH}$ plus rituximab increases progression-free survival (PFS) and has fewer toxic effects than the standard R-CHOP regimen (RIT, cyclophosphamide (CPA), doxorubicin (DOX), and vincristine (VCR)) in previously untreated patients with MCL (5). BH also has clinical activity in patients with relapsed NHL, including those refractory to other alkylating agents and purine analogs $(5,6)$. However, relapse occurs in most treated cases of MCL (7), and little is known about the mechanisms of resistance to BH. In this study, we investigated the molecular profiles of a novel MCL cell line with acquired $\mathrm{BH}$ resistance, with the goal of identifying the mechanism of resistance as a basis for development of a strategy to overcome $\mathrm{BH}$ resistance in treatment of MCL.

\section{Materials and Methods}

Establishment of cell lines. Primary lymphoma cells were isolated from peripheral blood of a MCL patient with informed consent, and were cultured in RPMI-1640 supplemented with $10 \%$ heat- 
inactivated fetal bovine serum, $2 \mathrm{mmol} / \mathrm{l} \mathrm{L}$-glutamine, and penicillin/streptomycin in a highly humidified atmosphere of $5 \%$ $\mathrm{CO}_{2}$ and $95 \%$ air at $37^{\circ} \mathrm{C}$. A novel cell line designated as KPUMYY1 was established after continuous culture for several months. KPUM-YY1 cells were subjected to continuous exposure to $\mathrm{BH}$ with gradual escalation of the concentration up to $50 \mu \mathrm{M}$, and a $\mathrm{BH}-$ resistant subline KPUM-YY1R was established. Subsequently, KPUM-YY1R cells were cultured and maintained by passage in a culture medium containing $50 \mu \mathrm{M}$ BH for over years. A human MCL-derived cell line, Jeko-1, was also used in some of the analyses below. The study was conducted in accordance with the ethical principles of the Declaration of Helsinki and with the approval of the institutional ethical review board of Kyoto Prefectural University of Medicine.

Cytogenetic and genome copy number analyses. Double colorfluorescence in situ hybridization (DC-FISH) and spectral karyotyping were performed as described previously $(8,9)$. The karyotype was described in accordance with the International System for Human Cytogenetic Nomenclature ISCN 2013 (10). Vysis IGH/CCND1 DF FISH and IGH/C-MYC DF FISH probe kits (Abbott Japan, Tokyo, Japan) were utilized for DC-FISH. A DNA gain and loss assay based on a SNP array (GeneChip Human Mapping 6.0 array; Affymetrix, Santa Clara, CA, USA) was performed on genomic DNA purified from KPUM-YY1 and KPUM-YY1R cells. The CNAG3.5.1 program was used for analysis of SNP array data to determine total copy numbers $(11,12)$.

Microarray analysis and signal pathway analysis. Comprehensive gene expression analysis was performed to compare gene expression profiles in KPUM-YY1 and KPUM-YY1R cells, using GeneChip arrays, a GeneChip Scanner 3000, and array data analysis with GeneChip software, v.1.0 (Affymetrix). Genes with at least a 1.5fold difference in expression between KPUM-YY1 and KPUMYY1R cells were considered positive. For signal pathway analysis, data were analyzed with Ingenuity software (Ingenuity Systems, Mountain View, CA, USA).

Assay for TP53 mutational status. TP53 gene mutational status was analyzed as described elsewhere (13).

Assays for growth inhibition and drug combination. Cells were treated with various concentrations of $\mathrm{BH}$ for $96 \mathrm{~h}$, and cytarabine (CA), DOX, etoposide (ETP), fludarabine (FLU), VCR (SigmaAldrich, St. Louis, MO), ibrutinib (Selleck Chemicals, Houston, TX), mafosfamide (the active metabolite of CPA, Santa Cruz Biotechnology, Dallas, TX, USA), lenalidomide (LEN) (Celgene Corp., Summit, NJ), melphalan, or BTZ (provided by the Screening Committee of Anticancer Drugs) for $48 \mathrm{~h}$, and cell viability was evaluated using a modified MTT assay in Cell Counting Kit-8 (Dojindo, Kumamoto, Japan). Cyclosporine A (Wako Pure Chemical Industries, Ltd., Osaka, Japan), verapamil (Sigma-Aldrich), PSC833, and C-4 (Santa Cruz Biotechnology) were utilized as inhibitors for $\mathrm{ABCB} 1$, and ethacrynic acid was used as a glutathione-S-transferase (GST) inhibitor (Sigma-Aldrich). Data are shown as the mean \pm standard error of three independent experiments.

Reverse-transcription-polymerase chain reaction (RT-PCR). RTPCR analysis was performed as described previously (12), using the following primers: ABCB1-S, 5'-CAC GTG GTT GGA AGC TAA
CC-3' and ABCB1-A, 5' -GAA GGC CAG AGC ATA AGA TGC-3' for detection of $A B C B 1$ expression; MGST1-S, 5'-ATT GGC CTC CTG TAT TCC TTG and MGST1-A, TAA TTC CTC TGC TCC CCT CC for detection of MGST1 expression, and $\beta$-actin-S, 5' -CTT CTA CAA TGA GCT GCG TG-3' and $\beta$-actin-A, 5'TCATGAGGTAGTCAGTCAGG-3' for detection of $\beta$-actin expression as an internal control.

Western blotting. Western blotting was performed as described previously (14), using a mouse monoclonal primary antibody for ABCB1 (D-11 clone; Santa Cruz Biotechnology) and an antibody to $\beta$-actin (Sigma-Aldrich) as an internal control.

\section{Results}

Establishment and cytogenetic features of KPUM-YYI cells. A 60-year-old male patient was diagnosed with MCL clinical stage IVA in the Ann Arbor staging system. The patient was treated with chemotherapies including R-CHOP, HyperCVAD/MTX-CA (CPA, VCR, DOX, dexamethasone (DEX), high-dose methotrexate (MTX) and CA), CHASE (CPA, highdose CA, DEX, ETP), cladribine, BTZ, irinotecan, Lasparaginase, gemcitabine, and $\mathrm{BH}$ for repeated relapse and remission, and eventually died of MCL progression after 17 years of treatment. A novel cell line, KPUM-YY1, was developed from circulating primary lymphoma cells collected from the patient in the terminal phase. KPUM-YY1 cells were morphologically round and medium in size with various forms of deformed nuclei (Figure 1A). These cells were maintained as a suspension culture in conventional culture medium. DCFISH for KPUM-YY1 cells identified the presence of fusion genes of immunoglobulin heavy chain $(I G H)$ and cyclin DI (Figure 1B) and of $I G H$ and $c-M Y C$ (Figure 1C). SKY analyses further revealed that KPUM-YY1 cells harbored complex karyotypic abnormalities, including a three-way translocation $\mathrm{t}(8 ; 14 ; 11)(\mathrm{q} 24 ; \mathrm{q} 32 ; \mathrm{q} 13)$, but not del17p (Figure 1D). This three-way translocation was also observed in patient-derived primary lymphoma cells (Data not shown).

Development of a BH-resistant subline KPUM-YY1R and its cytogenetic and molecular characteristics. The patient exhibited clinical resistance to BH, but growth of KPUM-YY1 cells was inhibited by $\mathrm{BH}$, with an $\mathrm{IC}_{50}$ of $20 \mu \mathrm{M}$ in 96-hour treatment in vitro (Figure $2 \mathrm{~A}$ ). To investigate the mechanisms underlying resistance to $\mathrm{BH}$, we sought to establish a $\mathrm{BH}$ resistant subline of KPUM-YY1. Continuous exposure to $\mathrm{BH}$ with gradual escalation of the $\mathrm{BH}$ concentration from 5 to 50 $\mu \mathrm{M}$ for 8 months generated a BH-resistant subline, KPUMYY1R, that was not inhibited by up to $60 \mu \mathrm{M} \mathrm{BH}$ and proliferated at $50.0 \mu \mathrm{M} \mathrm{BH}$ (Figure $2 \mathrm{~A}$ and $\mathrm{B}$ ).

To dissect the cytogenetic and molecular characteristics of this subline, including those associated with $\mathrm{BH}$ resistance, comparative analyses of cytogenetics and gene expression profiles (GEPs) in KPUM-YY1 and KPUM-YY1R cells were performed using SKY, genome copy number, and 
A

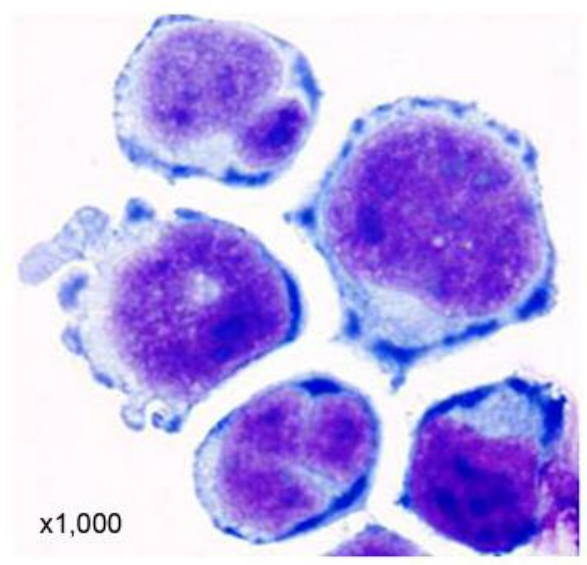

B

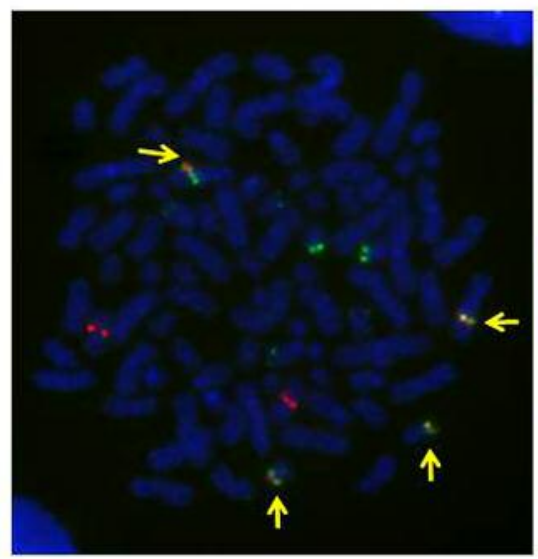

C

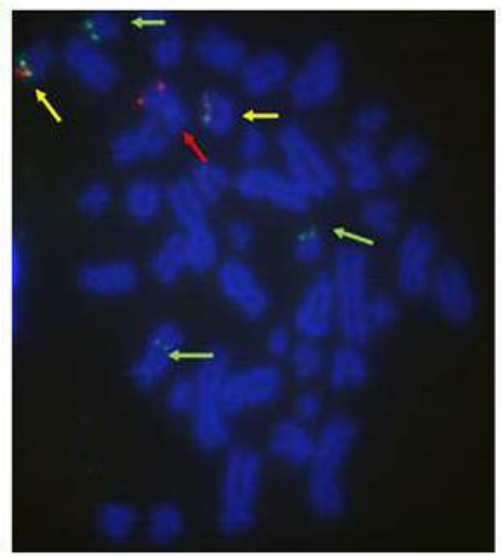

D

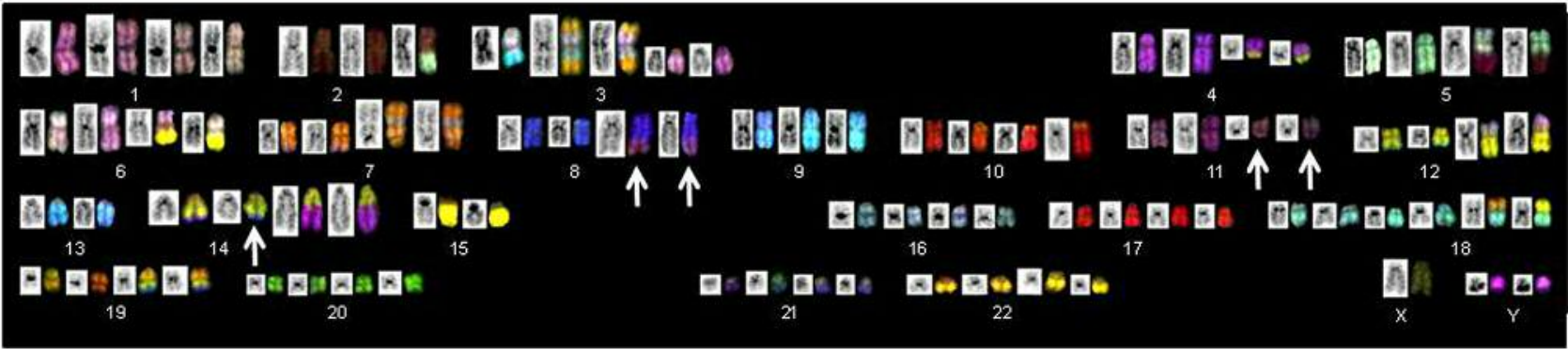

Figure 1. Morphological and cytogenetic features of KPUM-YY1 cells. A: Morphology of KPUM-YY1 cells. Cells were cytospinned and stained using Diff-Quik (Sysmex, Kobe, Japan), and the morphology was examined under a light microscope (magnification $\times 1,000)$. B: Metaphase double color (DC)-fluorescence in situ hybridization (FISH) analysis for immunoglobulin heavy chain (IgH) and cyclin D1 (CCND1) in KPUM-YY1 cells. Red and green signals indicate CCND1 at $11 q 13$ and IgH at 14q32, respectively. Yellow signals (arrows) indicate fusion of red and green signals, confirming the reciprocal translocation IgH/CCND1. C: Metaphase DC-FISH analysis for IgH and c-MYC in KPUM-YY1 cells. Red and green signals indicate cMYC at $8 q 24$ (red arrows) and IgH at 14q32 (green arrows), respectively. Yellow signals (arrows) indicate fusion of red and green signals, confirming the reciprocal translocation IgH/c-MYC. D: SKY analysis of KPUM-YY1 cells. The representative karyotype of KPUM-YY1 is 4n: 88, YY, inv(X) $(p 11 q 28), t(2 ; 5)(q 21 ; q 15),-2, \operatorname{del}(3)(p 12) x 2,+\operatorname{der}(3) t(3 ; 13)(q 12 ; q 14), \operatorname{der}(3)(7 q t e r \rightarrow 7 q 22:: 3 p 21 \rightarrow 3 q 21:: 13:: 7 q 11.2 \rightarrow 7 q t e r) x 2, t(4 ; 14)(q 12 ; q 32.1) x 2$, $\operatorname{der}(5) t(2 ; 5), \quad \operatorname{der}(6) t(6 ; 8)(p 25 ; q 24) x 2, \quad \operatorname{der}(6) t(6 ; 15)(q 13 ; q 11) x 2, \quad \operatorname{add}(7)(q 22) x 2, \quad \operatorname{der}(7)(7 q t e r \rightarrow 7 q 11.2:: 8:: 7 p 22 \rightarrow 7 q 11.2:: 7 p 22 \rightarrow 7 p t e r) x 2$, $t(8 ; 14 ; 11)(q 24 ; q 32 ; q 13) x 2, \operatorname{dup}(9)(p 13 p 24) x 3,-9, \operatorname{der}(10) t(10 ; 19)(p 15 ; q 13) x 2, t(12 ; 18)(q 15 ; p 11.2) x 2, \operatorname{der}(12) t(3 ; 12)(p 21 ; p 11.2) x 2,-13 \times 2,-15 x 2$, $+18 x 2, \operatorname{der}(19)(19 p t e r \rightarrow 19 q 13.1:: 14 q 24 \rightarrow 14 q 32:: 8 q 24 \rightarrow 8 q$ ter $) x 2$. Arrows indicate a three-way translocation $t(8 ; 14 ; 11)(q 24 ; q 32 ; q 13)$.

expression microarray analyses. Several cytogenetic abnormalities were identified in KPUM-YY1R cells that were not present in parental KPUM-YY1 cells in SKY and genome array analyses (Table I, Figure 2C and D).

In GEP analyses, 312 genes were up-regulated more than 1.5 -fold and 160 genes were down-regulated to less than 0.67-fold in KPUM-YY1R cells compared with KPUM-YY1 cells (Data not shown). Genes upregulated in KPUM-YY1R cells included $A B C B 1$ (1.79-fold), and the Ingenuity canonical signal pathway analysis based on the GEP results suggested that KPUM-YY1R cells harbored distinct gene expression patterns in the glutathione S-transferase (GST) family, such as MGST1 (3.23-fold), GSTA4, or GSTM2 (Table II). Indeed, overexpression of MDRI and MGSTI was confirmed by RT-PCR (Figure 2E) and an increase of P-gp was found at the protein level (Figure 2F). Eleven of 472 genes with differential expression in GEP were associated with additional genomic regions identified by SKY and genome copy number analyses in KPUM-YY1R cells (Table I), but none had previously been associated with drug resistance. In addition, TP53 mutation was absent in KPUMYY1 and KPUM-YY1R cells (data not shown).

$A B C B 1$ and MGSTl are involved in resistance to $B H$ in KPUM-YYIR cells. Based on the above results, we focused on the ABCB1 and GST families as candidate causes of acquisition of resistance to BH in KPUM-YY1R cells. Addition of an inhibitor of $\mathrm{ABCB} 1$ protein $(5 \mu \mathrm{M}$ 
cyclosporine A, $10 \mu \mathrm{M}$ verapamil, $5 \mu \mathrm{M}$ PSC833, or $5 \mu \mathrm{M}$ $\mathrm{C}$-4) partly restored the sensitivity to BH in KPUM-YY1R cells (Figure 3A, B, C and D). Perhaps consistent with faint expression of ABCB1 protein in parental KPUM-YY1 cells (Figure 2F), addition of ABCB1 inhibitors also enhanced the growth inhibitory effect of BH in KPUM-YY1 cells, although the degree of enhancement was much smaller compared with that in KPUM-YY1R cells. Similarly, addition of $30 \mu \mathrm{M}$ ethacrynic acid, a GST inhibitor, partly restored sensitivity to BH in KPUM-YY1R cells (Figure 3E). These results indicate the functional significance of upregulation of $A B C B 1$ and MGST1 in development of $\mathrm{BH}$ resistance in MCL.

Cross-resistance to other chemotherapeutic agents in KPUM-YY1R cells. Compared to parental KPUM-YY1 cells, KPUM-YY1R cells showed partial cross-resistance to DOX, mafosfamide, melphalan, VCR and ibrutinib (Figure 4), whereas sensitivity to cytarabine, ETP, FLU, BTZ, and LEN, which are used in treatment of MCL, were mostly equivalent in the two cell lines (Figure 5).

\section{Discussion}

$\mathrm{BH}$ is a unique anticancer agent since it structurally consists of three active moieties: an alkylating group, in common with the nitrogen mustard family; a benzimidazole ring, which may act as a purine analog; and a butyric acid sidechain. Therefore, BH may have antitumor effects against various types of cancers. At present, $\mathrm{BH}$ is used as a central therapeutic component in both first-line and salvage strategies for various types of low grade B-cell NHLs and for MCL, a usually aggressive and difficult-to-treat disease subtype, in the clinical setting (15-19). Regarding its mechanisms of action, $\mathrm{BH}$ alkylates and crosslinks DNA, leading to double-strand breaks (DSBs) followed by p53dependent and -independent apoptosis in cancer cells, with formation of DSBs that is more powerful and long-lasting than other alkylating agents. In addition, unlike other alkylators, BH can also induce mitotic catastrophe via inhibition of mitotic checkpoint regulators such as polo-like kinase 1, aurora kinase A, or cyclin B1 (6, 17, 20, 21). Due to these overlapping mechanisms, $\mathrm{BH}$ has only partial in vitro cross-resistance with other alkylators, such as CPA or melphalan (17), and has full antitumor activity in anthracycline-resistant and platinum-drug resistant cell lines (20). These findings may explain the efficacy of $\mathrm{BH}$ for both treatment-naïve and relapsed patients with indolent NHL, including those who have lost responsiveness to other alkylating agents or purine analogs $(5,20)$. In addition, $\mathrm{BH}$ has been shown to exert synergistic cytotoxicity with BTK inhibitors on MCL-derived cell lines, implicating its further therapeutic application (22).
The molecular mechanism for resistance to $\mathrm{BH}$ has not been investigated as intensively as the mechanism of action. However, acquisition of clinical resistance to $\mathrm{BH}$ is a critical event that potentially determines the life expectancy of patients with B-cell NHL, and especially MCL, and there is an urgent need to understand the mechanisms underlying resistance to $\mathrm{BH}$. To answer this question, in this study we developed a novel MCL-derived cell line, KPUM-YY1, and a BH-resistant subline, KPUM-YY1R, by continuous in vitro exposure to $\mathrm{BH}$, and performed comparative analysis of the molecular profiles of these cells. Using this approach, we found that upregulation of $A B C B I$ and $G S T$, which occurs commonly in drug resistance mechanisms (23), contributed to acquisition of resistance to $\mathrm{BH}$, and we also showed that acquisition of resistance to $\mathrm{BH}$ has a potential risk for acquisition of cross-resistance to anti-lymphoma chemotherapeutics such as DOX, mafosfamide, melphalan, and VCR.

Figure 2. Cellular and cytogenetic/molecular characteristics of bendamustine (BH)-resistant KPUM-YYIR cells. A: Growth inhibitory effect of BH on KPUM-YY1 and KPUM-YY1R cells. Cells were treated with $B H$ for $96 h$ and cell viability was evaluated by a modified MTT assay. Data are shown as means+/-standard errors from triplicate experiments. Growth of KPUM-YY1 cells was inhibited by BH in a dosedependent manner, while growth of KPUM-YYIR cells was not inhibited by $60 \mu M B H$. B: Growth curves of KPUM-YYI and KPUM-YY1R cells. KPUM-YY1 cells were cultured in normal medium, while KPUM-YY1R cells were grown in culture medium containing $50 \mu \mathrm{M} \mathrm{BH}$. Cells were stained by Trypan Blue and viable cell numbers were counted under an inverted microscope. C: SKY analysis of KPUM-YYIR cells. The representative karyotype of KPUM-YY1R cells is 4n: 84, YY, $\operatorname{inv}(X)(p 11 q 28) x 2, \quad \operatorname{der}(1) t(1 ; 7)(p 32 ; q 11.2), \quad t(2 ; 5)(q 21 ; q 15), \quad-2$, $\operatorname{del}(3)(p 12) x 2,+\operatorname{der}(3) t(3 ; 13)(q 12 ; q 14), \operatorname{der}(3)(7 q t e r \rightarrow 7 q 22: \because 3 p 21 \rightarrow 3 q 21$ $\because: 13:: 7 q 11.2 \rightarrow 7 q t e r) x 2, t(4 ; 14)(q 12 ; q 32.1), \operatorname{der}(4) t(4 ; 14), \operatorname{der}(5) t(2 ; 5)$, $\operatorname{der}(5) t(5 ; 9)(q 11 ; p 13), \operatorname{der}(6) t(6 ; 15)(q 13 ; q 11), \operatorname{der}(6) t(6 ; 8)(p 25 ; q 24) x 2$, $\operatorname{dic}(6 ; 20)(p 21 ; q 13),-6, \operatorname{add}(7)(q 22) x 2$, der(7)(7qter $\rightarrow 7 q 11.2:: 8:: 7 p 22 \rightarrow$ $7 q 11.2: \because 7 p 22 \rightarrow 7 p t e r) x 2, \quad t(8 ; 14 ; 11)(q 24 ; q 32 ; q 13) x 2, \quad \operatorname{del}(9)(q 21)$, $\operatorname{der}(9)(9 p t e r \rightarrow 9 q 22: \because 13:: 5),-9,-9$, der(10)t(10;19)(p15;q13)x2, der(10) $(5 q$ ter $\rightarrow 5 q 15:: 2 q 21 \rightarrow 2 q 13:: 10 p 11 \rightarrow 10 q t e r), \quad t(12 ; 18)(q 15 ; p 11.2) \times 2$, $\operatorname{der}(12) t(3 ; 12)(p 21 ; p 11.2) x 2, \operatorname{der}(13) t(1 ; 13)(p 22 ; q 32) x 2,+13,-14,-15,-$ $15,+18, \operatorname{der}(19)(19 p t e r \rightarrow 19 q 13.1:: 14 q 24 \rightarrow 14 q 32:: 8 q 24 \rightarrow 8 q$ ter $) x 2,-20$, $-20,-20,-21$. Arrows indicate a three-way translocation $t(8 ; 14 ; 11)(q 24 ; q 32 ; q 13)$. D: Genome copy number analysis in KPUM$Y Y 1 R$ cells. A DNA gain and loss assay based on a SNP array was performed on genomic DNA purified from KPUM-YYIR cells. The CNAG3.5.1 program was used for analysis of SNP array data to determine total copy numbers. E: RT-PCR analyses for ABCB1 and $M G S T 1$. Transcriptional expression of ABCB1 and MGST1 was examined in KPUM-YY1 cells, KPUM-YY1R cells, normal B lymphocytes, and Jeko-1 cells (MCL-derived cell line). $\beta$-Actin was used as an internal control. F: Western blot for ABCB1 protein. ABCB1 protein expression was examined in KPUM-YY1 cells, KPUM-YY1R cells, normal B lymphocytes, and Jeko-1 cells, with $\beta$-Actin used as an internal control. 

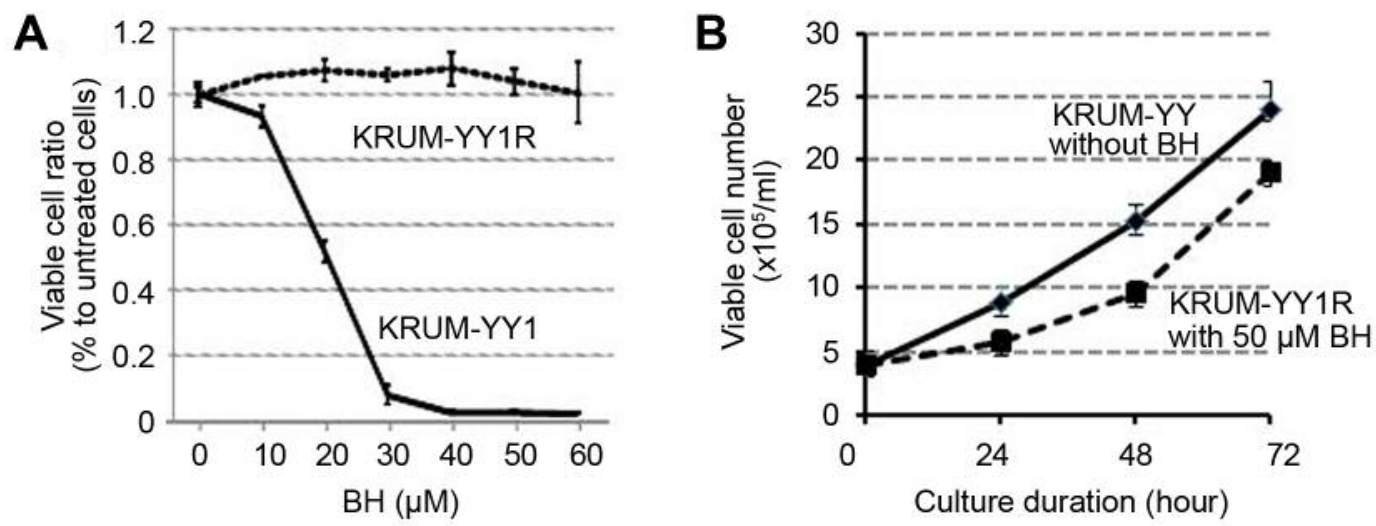

C

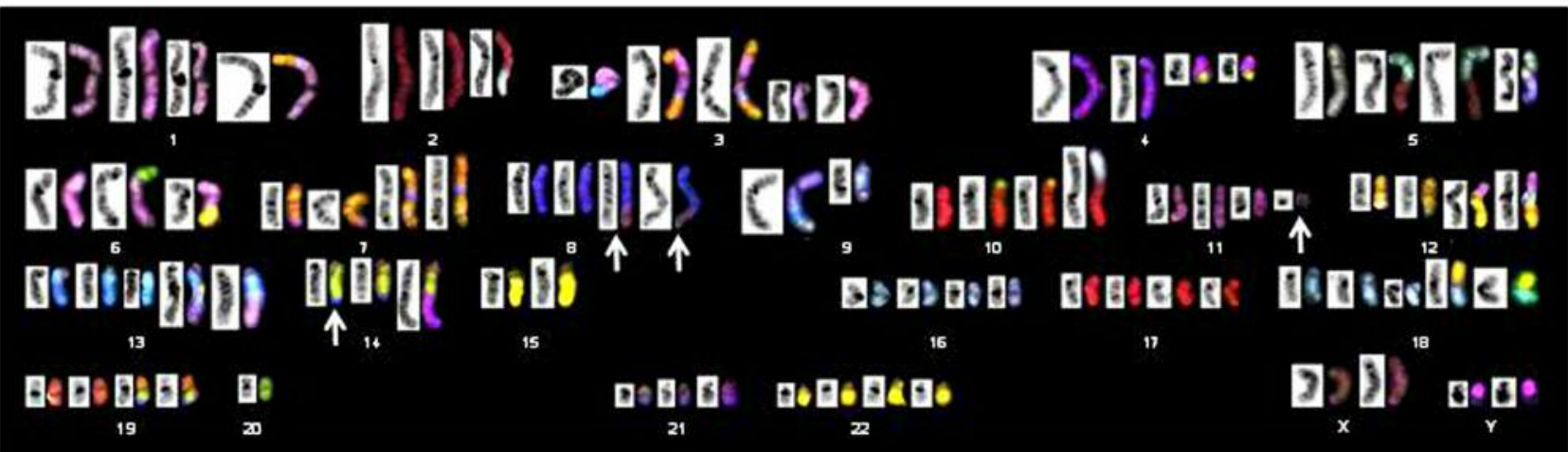

D

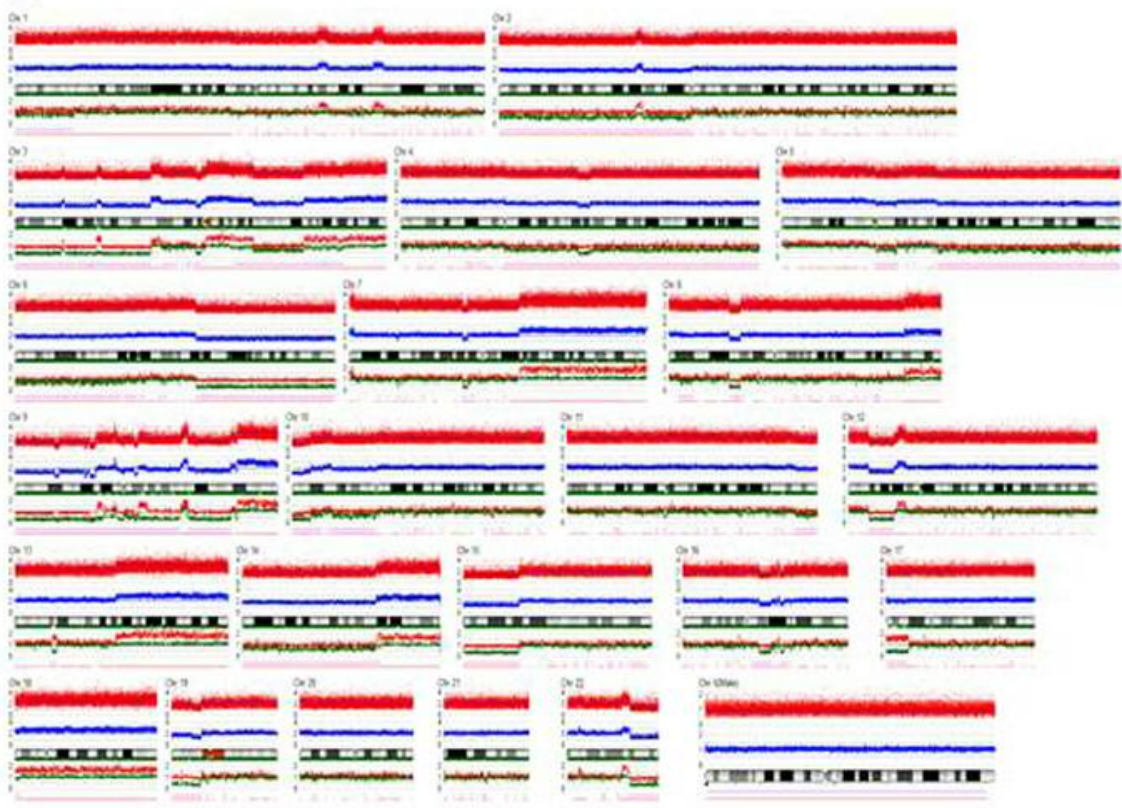

E

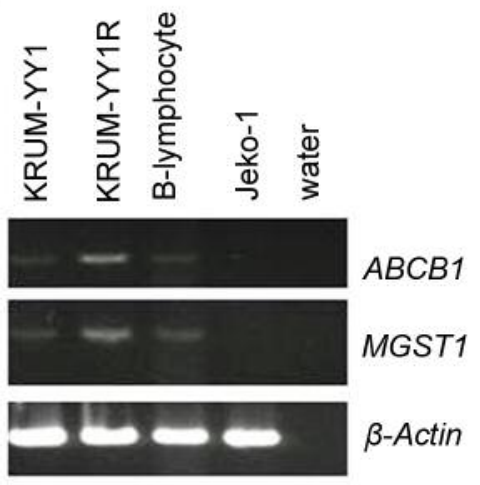

F

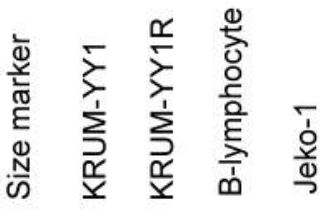

ABCB1 
Table I. Comparison of cytogenetic and gene expression analysis between KPUM-YY1 and KPUM-YY1R cells.

\begin{tabular}{|c|c|c|c|c|}
\hline \multirow[t]{2}{*}{ Method } & \multirow[t]{2}{*}{ KPUM-YY1 } & \multirow[t]{2}{*}{ KPUM-YY1R } & \multicolumn{2}{|c|}{ Differentially expressed genes in GEP } \\
\hline & & & Up-regulated & Down-regulated \\
\hline \multirow[t]{6}{*}{ SKY } & & $\operatorname{der}(1) \mathrm{t}(1 ; 7)(\mathrm{p} 32 ; \mathrm{q} 11.2)$ & ZYG11A, CDKN2C, JUN & \\
\hline & & $\operatorname{der}(5) \mathrm{t}(5 ; 9)(\mathrm{q} 11 ; \mathrm{p} 13)$ & ANKRD18A & CNTNAP3 \\
\hline & & $\operatorname{der}(9)(9$ pter $\rightarrow 9 q 22:: 13:: 5)$ & & \\
\hline & & $\operatorname{der}(10)(5 \mathrm{qter} \rightarrow 5 \mathrm{q} 15:: 2 \mathrm{q} 21 \rightarrow 2 \mathrm{q} 13:: 10 \mathrm{p} 11 \rightarrow 10 \mathrm{qter})$ & & \\
\hline & & $\operatorname{der}(13) \mathrm{t}(1 ; 13)(\mathrm{p} 22 ; \mathrm{q} 32)$ & & \\
\hline & & -9 & & \\
\hline \multirow[t]{13}{*}{ Genome Array } & & $1 \mathrm{p} 13.3-1 \mathrm{p} 35.1$ gain & ZYG11A, IFI44, IFI44L & \\
\hline & & & SORT1, JUN, MANEAL & \\
\hline & & $2 \mathrm{q} 11.2-2 \mathrm{q} 21.2$ gain & & \\
\hline & & $3 q 13.11$ gain & & \\
\hline & & $4 \mathrm{q} 12-4 \mathrm{q} 22.1$ loss & IGJ & \\
\hline & & $5 q 11.1-5 q 12.1$ loss & & \\
\hline & & $10 \mathrm{p} 11.110 \mathrm{p} 13$ loss & LYZL1 & \\
\hline & & 10 p14 loss & & \\
\hline & & $10 \mathrm{p} 15.1-10 \mathrm{p} 15.3$ loss & & \\
\hline & $11 \mathrm{p} 14.3$ loss & & & \\
\hline & & $16 \mathrm{q} 12.2-16 \mathrm{q} 21$ loss & & \\
\hline & & $16 \mathrm{q} 21$ loss & & \\
\hline & & 16q21 mgain & & \\
\hline
\end{tabular}

Table II. Top ingenuity canonical pathways enriched by genes that were significantly differentially up-regulated in KPUM-YY1R cells.

\begin{tabular}{lccc}
\hline Ingenuity canonical pathways & $-\log (p-$ Value $)$ & Ratio & Molecules \\
\hline Epithelial adherence junction signaling & $2.60 \mathrm{E}+00$ & $5.19 \mathrm{E}-02$ & $\begin{array}{c}\text { MAGI1, LMO7, LEF1, TCF3, } \\
\text { NOTCH1, ACVR2A, TCF7L2, CTNND1 }\end{array}$ \\
Factors promoting cardiogenesis in vertebrates & & & FZD, LEF1, MEF2C, TCF3, ACVR2A, TCF7L2 \\
Glutathione - mediated detoxification & $2.53 \mathrm{E}+00$ & $6.06 \mathrm{E}-02$ & MGST1, GSTM2, GSTA4 \\
Autoimmune thyroid disease signaling & $2.22 \mathrm{E}+00$ & $6.82 \mathrm{E}-02$ & CD80, TSHR, CD86 \\
Mouse embryonic stem cell pluripotency & $1.79 \mathrm{E}+00$ & $4.84 \mathrm{E}-02$ & ID1, FZD6, LEF1, TCF3, TCF7L2 \\
Human embryonic stem cell pluripotency & $1.71 \mathrm{E}+00$ & $5.05 \mathrm{E}-02$ & S1PR4, PDGFA, FZD6, LEF1, TCF3, TCF7L2 \\
Aryl hydrocarbon receptor signaling & $1.70 \mathrm{E}+00$ & $3.70 \mathrm{E}-02$ & MGST1, GSTM2, JUN, NFIA, GSTA4, NRIP1 \\
Role of Wnt/GSK-3 signaling in the pathogenesis of influenza & $1.66 \mathrm{E}+00$ & $3.51 \mathrm{E}-02$ & FZD6, LEF1, TCF3, TCF7L2 \\
Type I diabetes mellitus signaling & $1.65 \mathrm{E}+00$ & $4.82 \mathrm{E}-02$ & CD3G, CD80, SOCS6, SOCS2, CD86 \\
Systemic lupus erythematosus signaling & $1.59 \mathrm{E}+00$ & $2.73 \mathrm{E}-02$ & CD3G, RNPC3, JUN, CD80, \\
& & & RNU4 CD86, RNU5A -1 \\
Basal cell carcinoma signaling & $1.58 \mathrm{E}+00$ & $5.13 \mathrm{E}-02$ & FZD6, LEF1, TCF3, TCF7L2 \\
Thyroid cancer signaling & $1.57 \mathrm{E}+00$ & $6.82 \mathrm{E}-02$ & LEF1, TCF3, TCF7L2 \\
Glutathione redox reactions I & $1.51 \mathrm{E}+00$ & $8.33 \mathrm{E}-02$ & MGST1, GPX7 \\
CD28 signaling in T helper cells & $1.51 \mathrm{E}+00$ & $3.68 \mathrm{E}-02$ & CD3G, PAK1, JUN, CD80, CD86 \\
Nur77 signaling in T lymphocytes & $1.41 \mathrm{E}+00$ & $4.69 \mathrm{E}-02$ & CD3G, CD80, CD86 \\
TNFR1 signaling & $1.41 \mathrm{E}+00$ & $5.56 \mathrm{E}-02$ & PAK1, JUN, TNFAIP3 \\
CTLA4 signaling in cytotoxic T lymphocytes & $1.35 \mathrm{E}+00$ & $4.17 \mathrm{E}-02$ & CD3G, CD80, CD86, PTPN22 \\
Diphthamide biosynthesis & $1.32 \mathrm{E}+00$ & $7.69 \mathrm{E}-02$ & DPH5
\end{tabular}

$A B C B 1$ encodes $\mathrm{P}$-gp, a plasma membrane drug efflux pump that causes resistance to its substrate anticancer agents, such as DOX, VCR, and ETP. Drugs that are potential inducers of Pgp are generally also substrates of this transporter, but recent studies have shown that several agents that are not transportable by P-gp can also induce P-gp overexpression. Moreover, P-gp has effects that are independent of its drug efflux activity, including effects on the function of TP53, 

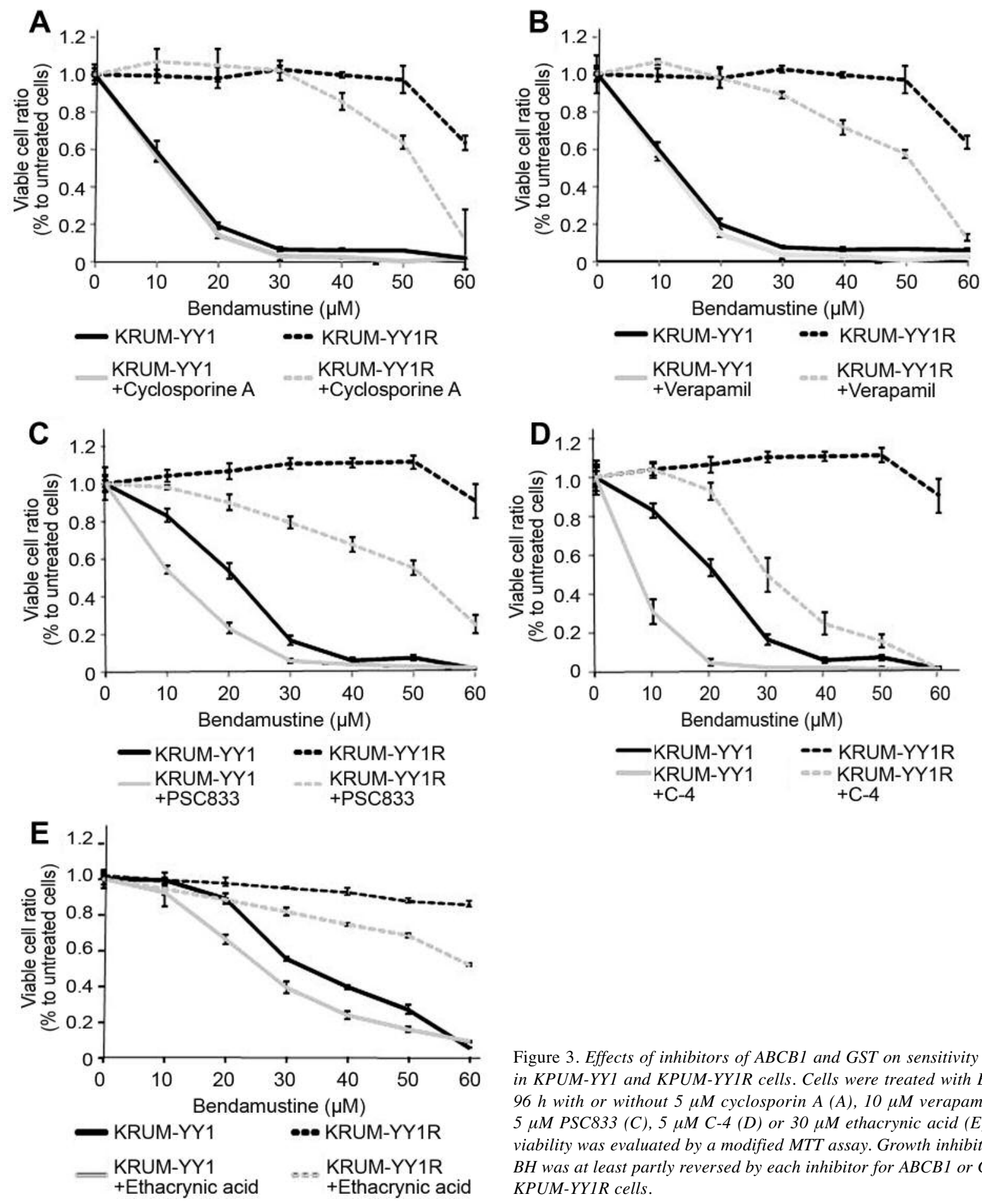

Figure 3. Effects of inhibitors of $A B C B 1$ and GST on sensitivity to $B H$ in KPUM-YY1 and KPUM-YYIR cells. Cells were treated with $B H$ for $96 h$ with or without $5 \mu M$ cyclosporin $A(A), 10 \mu M$ verapamil $(B)$, $5 \mu M$ PSC833 (C), $5 \mu M$ C-4 (D) or $30 \mu M$ ethacrynic acid (E). Cell viability was evaluated by a modified MTT assay. Growth inhibition by $B H$ was at least partly reversed by each inhibitor for ABCB1 or GST in KPUM-YY1R cells.

survivin, caspases, protein expression, glycosylation and phosphorylation, which may collectively induce changes in cell sensitivity to agents that are not P-gp substrates (24-27). Indeed, $\mathrm{BH}$ has not been proven to be a substrate for the P-gp drug efflux pump; therefore, we speculate the possible involvement of drug efflux pump-independent mechanisms for the acquisition of resistance to BH in KPUM-YY1R cells. Irradiation-induced P-gp overexpression has been associated 

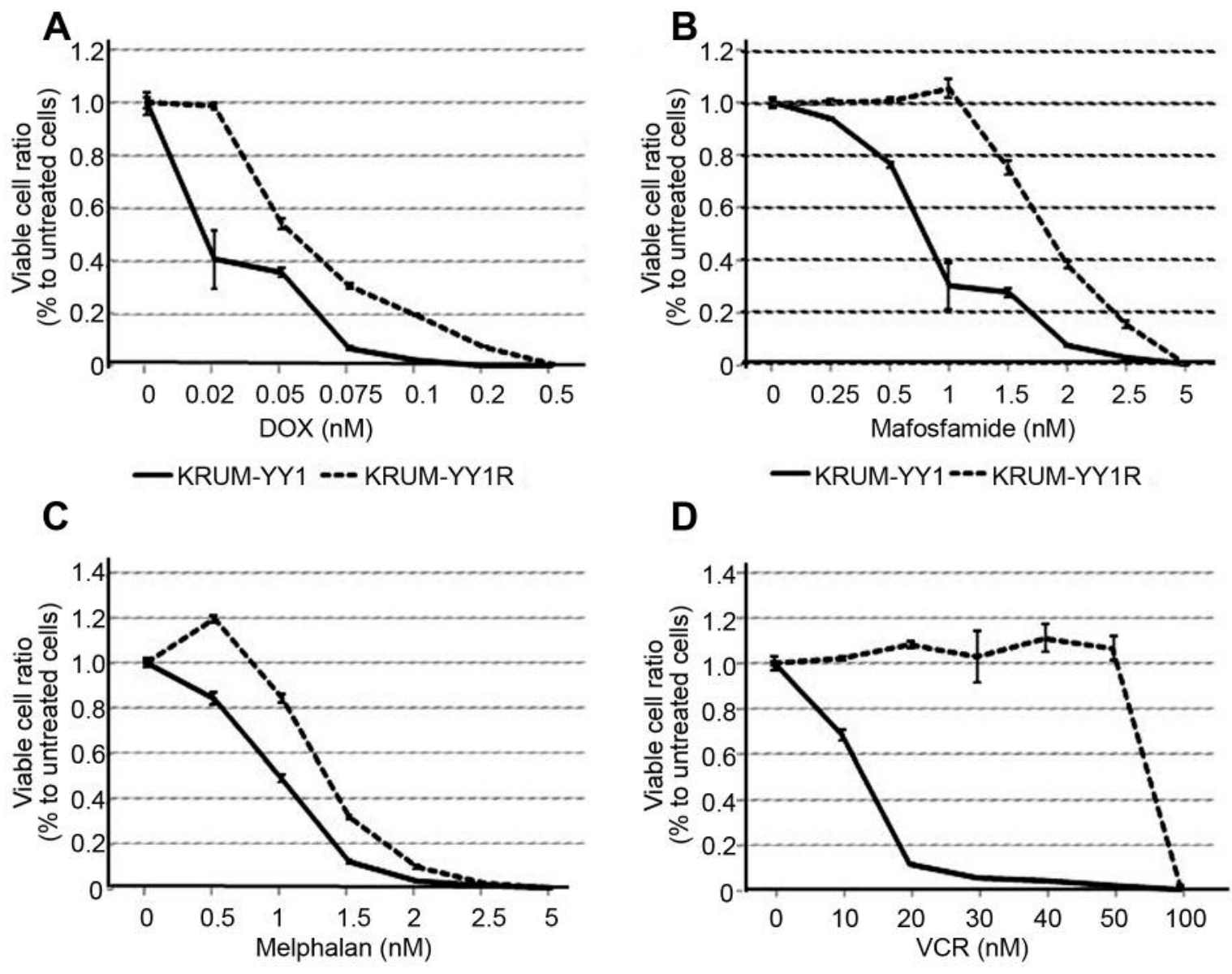

一KRUM-YY1---KRUM-YY1R

\section{E}

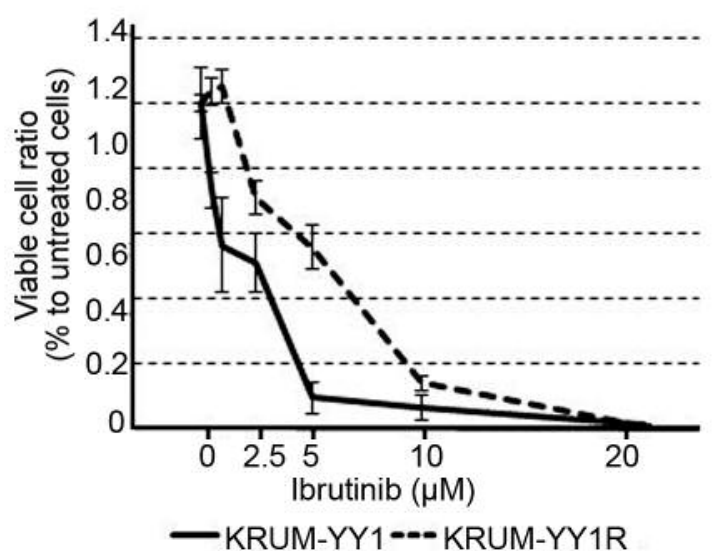

with resistance to BH in colorectal cancer cell lines (28). The pathway through which continuous exposure to BH causes upregulation of $A B C B 1$ is uncertain, but resistance to $\mathrm{BH}$ is at least partly reversed by addition of P-gp antagonists, as for resistance to anthracyclines or vinca alkaloids $(29,30)$.

Figure 4. Cross resistance against various anticancer agents in KPUM$Y Y 1 R$ cells. KPUM-YY1 and KPUM-YYIR cells were treated with anticancer agents for $48 \mathrm{~h}$ and subjected to modified MTT assays. KPUM-YYIR cells showed resistance to $(A)$ doxorubicin (DOX) $\left(I C_{50}\right.$ : 0.019 and $0.069 \mu M$ in KPUM-YY1 and KPUM-YY1R cells, respectively), (B) mafosfamide $\left(I C_{50}: 0.74\right.$ and $\left.1.64 \mu \mathrm{M}\right)$, (C) melphalan $\left(I C_{50}: 0.83\right.$ and $\left.1.85 \mu \mathrm{M}\right),(D)$ vincristine $\left(I_{50}: 10.83\right.$ and $\left.63.88 \mathrm{nM}\right)$, and $(E)$ ibrutinib $\left(I C_{50}: 2.63\right.$ and $\left.6.28 \mu \mathrm{M}\right)$.

Conjugation with glutathione mediated by GSTs is a major route of bendamustine metabolism (31). GSTs are a complex multigene family of enzymes that detoxify electrophilic xenobiotics such as alkylating agents, such that overexpression of GSTs is associated with resistance to 


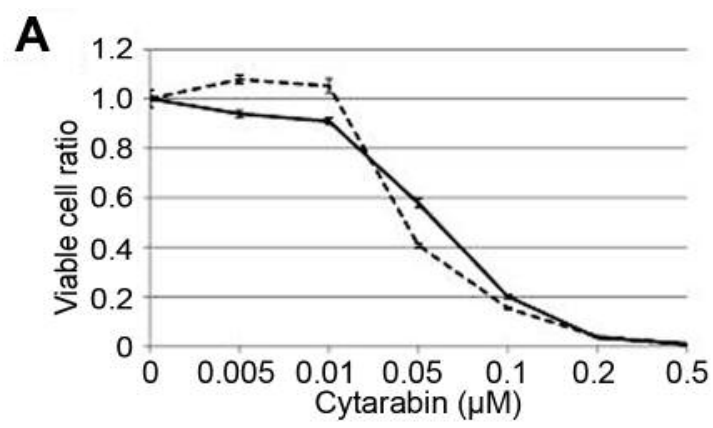

一 KRUM-YY1---KRUM-YY1R

B
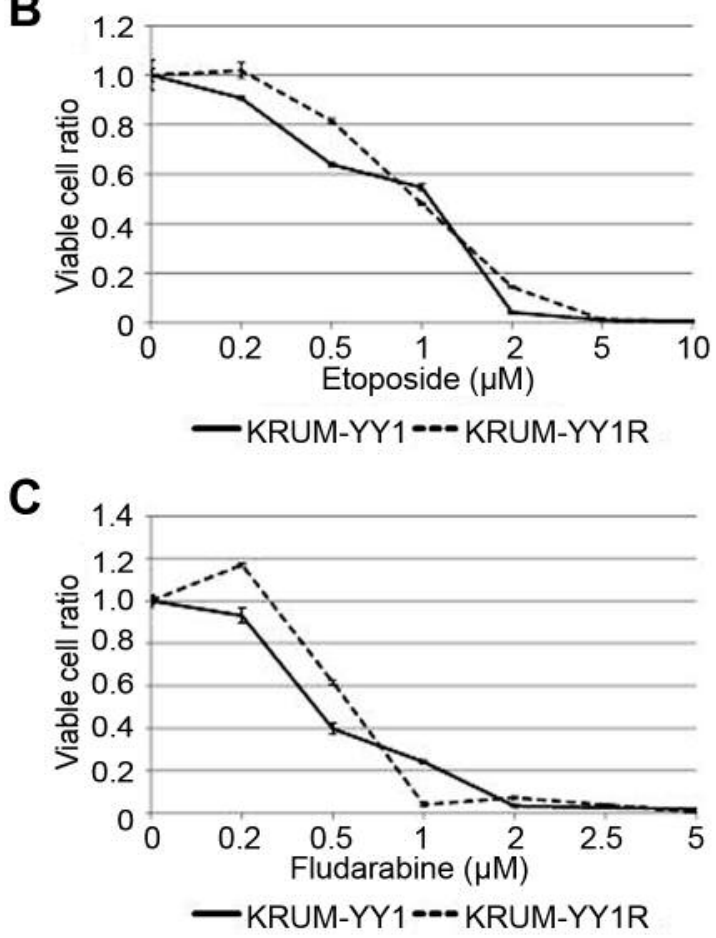

alkylating agents or anthracyclines. Basic glutathione levels and GST activity showed no correlation to sensitivity to BH in previous studies $(20,32,33)$, but we found that inhibition of GSTs partly restored the sensitivity to BH in KPUMYY1R cells. Thus, we speculate that sensitivity and resistance to BH is associated with the GST level or another effect of GST that is cell- or tumor-dependent. There is no clinically available inhibitor for ABCB1 or GST, which suggests the importance of an appropriate clinical sequence of therapeutic agents for MCL. That is, once resistance to $\mathrm{BH}$ is acquired, use of agents with effects unrelated to P-gp or GST might be most rational.

There are some limitations to this study. We first established a parental KPUM-YY1 cell line from a patient with MCL who developed clinical resistance to $\mathrm{BH}$, and it

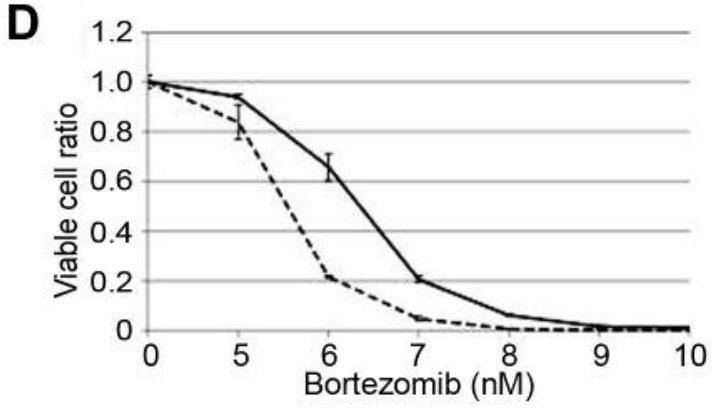

一KRUM-YY1---KRUM-YY1R

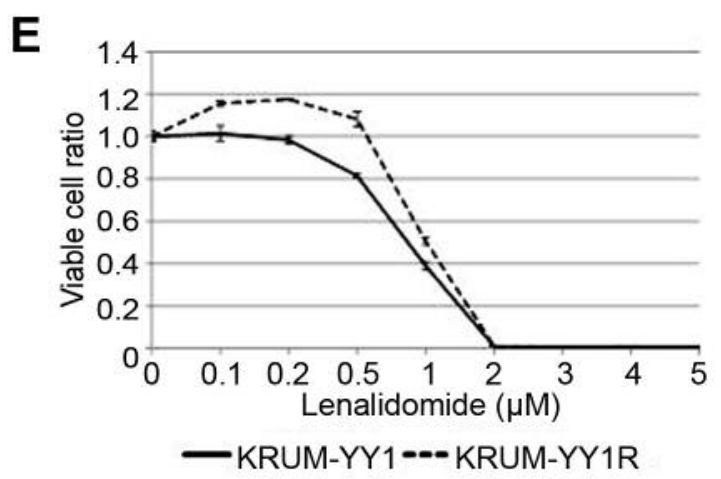

Figure 5. Sensitivity of KPUM-YY1 and KPUM-YY1R cells to chemotherapeutic agents. Cells were treated with anticancer agents for $48 \mathrm{~h}$ and cell viability was evaluated by a modified MTT assay. There was no significant difference between KPUM-YY1 and KPUM-YY1R cells in sensitivity to $(A)$ cytarabine, $(B)$ etoposide, $(C)$ fludarabine, $(D)$ bortezomib, or (E) lenalidomide.

might have been expected that this cell line should also be resistant to BH. However, KPUM-YY1 cells retain sensitivity to various anticancer agents, including $\mathrm{BH}$, in in vitro experiments. The precise reason for this discrepancy is unclear, but we speculate that there are additional mechanisms other than the ABCB1 and GST pathways for clinical resistance to $\mathrm{BH}$ in vivo, such as a protective effect of the tumor microenvironment or dysregulation of the pharmacological metabolism. It is also conceivable that the clonal tide during treatment may cause the discrepancy. Given that the patient was first sensitive to $\mathrm{BH}$ and then acquired clinical resistance, the BH-resistant clone might have become predominant after long exposure to $\mathrm{BH}$ in development of clinical resistance, but there could still be a small residual population of BH-sensitive clones, and the parental KPUM- 
YY1 cells could have been mostly derived from this population. Regardless, the results showed involvement of ABCB1 and GST family proteins in acquisition of BHresistance and secondary multidrug resistance in a MCLderived cell line, but unknown mechanisms may also account for clinical resistance to $\mathrm{BH}$. It will be important to investigate the clinical role of upregulation of $\mathrm{ABCB} 1$ or GST family proteins in MCL in a future study.

In conclusion, this study, for the first time, showed that common multidrug resistance mechanisms, such as ABCB1 and GSTs, underlie resistance to $\mathrm{BH}$, and that acquisition of $\mathrm{BH}$ resistance potentially leads to multidrug resistance in MCL. The newly-developed KPUM-YY1 and KPUM-YY1R cells allowed identification of multiple mechanisms underlying BH activity and resistance, and may facilitate development of a strategy that overcomes treatment refractoriness in MCL.

\section{Acknowledgements}

The Authors are grateful to T. Ikawa and Y. Yamane for their excellent technical assistance. This work was supported in part by a Grant-inAid for Scientific Research from The Ministry of Education, Culture, Sports, Science and Technology of Japan (MEXT KAKENHI 16K09856) (MT); a Grant-in-Aid for Young Scientists (B) (JSPS KAKENHI Grant Number JP16K21284) (YC); the National Cancer Center Research and Development Fund (29-A-3); a grant (Practical Research for Innovative Cancer Control) from the Japan Agency for Medical Research and Development (AMED) (17ck0106348h0001); and by the Takeda Science Foundation and Astra Zeneca (JK).

\section{References}

1 Lenz G, Dreyling M, Hoster E, Wörmann B, Dührsen U, Metzner B, Eimermacher H, Neubauer A, Wandt H, Steinhauer H, Martin S, Heidemann E, Aldaoud A, Parwaresch R, Hasford J, Unterhalt $\mathrm{M}$ and Hiddemann W: Immunochemotherapy with rituximab and cyclophosphamide, doxorubicin, vincristine, and prednisone significantly improves response and time to treatment failure, but not long-term outcome in patients with previously untreated mantle cell lymphoma: results of a prospective randomized trial of the German Low Grade Lymphoma Study Group (GLSG). J Clin Oncol 23(9): 1984-1992, 2005.

2 Wang ML, Rule S, Martin P, Goy A, Auer R, Kahl BS, Jurczak W, Advani RH, Romaguera JE, Williams ME, Barrientos JC, Chmielowska E, Radford J, Stilgenbauer S, Dreyling M, Jedrzejczak WW, Johnson P, Spurgeon SE, Li L, Zhang L, Newberry K, Ou Z, Cheng N, Fang B, McGreivy J, Clow F, Buggy JJ, Chang BY, Beaupre DM, Kunkel LA and Blum KA: Targeting BTK with ibrutinib in relapsed or refractory mantlecell lymphoma. N Engl J Med 369(6): 507-516, 2013.

3 Robak T, Huang H, Jin J, Zhu J, Liu T, Samoilova O, Pylypenko H, Verhoef G, Siritanaratkul N, Osmanov E, Alexeeva J, Pereira J, Drach J, Mayer J, Hong X, Okamoto R, Pei L, Rooney B, van de Velde H Cavalli F and LYM-3002 Investigators: Bortezomibbased therapy for newly diagnosed mantle-cell lymphoma. $\mathrm{N}$ Engl J Med 372(10): 944-953, 2015.
4 Dreyling M, Lenz G, Hoster E, Van Hoof A, Gisselbrecht C, Schmits R, Metzner B, Truemper L, Reiser M, Steinhauer H, Boiron JM, Boogaerts MA, Aldaoud A, Silingardi V, KluinNelemans HC, Hasford J, Parwaresch R, Unterhalt $M$ and Hiddemann W: Early consolidation by myeloablative radiochemotherapy followed by autologous stem cell transplantation in first remission significantly prolongs progression-free survival in mantle-cell lymphoma: results of a prospective randomized trial of the European MCL Network. Blood 105(7): 2677-2684, 2005.

5 Friedberg JW, Cohen P, Chen L, Robinson KS, Forero-Torres A, La Casce AS, Fayad LE, Bessudo A, Camacho ES, Williams ME, van der Jagt RH, Oliver JW and Cheson BD: Bendamustine in patients with rituximab-refractory indolent and transformed non-Hodgkin's lymphoma: results from a phase II multicenter, single-agent study. J Clin Oncol 26(2): 204-210, 2008.

6 Roué G, López-Guerra M, Milpied P, Pérez-Galán P, Villamor $\mathrm{N}$, Montserrat E, Campo E and Colomer D: Bendamustine is effective in p53-deficient B-cell neoplasms and requires oxidative stress and caspase-independent signaling. Clin Cancer Res 14(21): 6907-6915, 2008.

7 Rummel MJ, Niederle N, Maschmeyer G, Banat GA, von Grünhagen U, Losem C, Kofahl-Krause D, Heil G, Welslau M, Balser C, Kaiser U, Weidmann E, Dürk H, Ballo H, Stauch M, Roller F, Barth J, Hoelzer D, Hinke A, Brugger W and Study Group Indolent Lymphomas (StiL): Bendamustine plus rituximab versus CHOP plus rituximab as first-line treatment for patients with indolent and mantle-cell lymphomas: an openlabel, multicentre, randomised, phase 3 non-inferiority trial. Lancet 381(9873): 1203-1210, 2013.

8 Taniwaki M, Sliverman GA, Nishida K, Horiike S, Misawa S, Shimazaki C, Miura I, Nagai M, Abe M, Fukuhara S and Kashima K: Translocations and amplification of the BCL2 gene are detected in interphase nuclei of non-Hodgkin's lymphoma by in situ hybridization with yeast artificial chromosome clones. Blood 86(4): 1481-1486, 1995.

9 Kakazu N, Taniwaki M, Horiike S, Nishida K, Tatekawa T, Nagai M, Takahashi T, Akaogi T, Inazawa J, Ohki M and Abe $\mathrm{T}$ : Combined spectral karyotyping and DAPI banding analysis of chromosome abnormalities in myelodysplastic syndrome. Genes Chromosomes Cancer 26(4): 336-345, 1999.

10 Shaffer LG, McGowan-Jordan J and Schmid M: ISCN 2013: An International system for human cytogenetic nomenclature. Basel, Switzerland: S. Karger, 2013.

11 Nannya Y, Sanada M, Nakazaki K, Hosoya N, Wang L, Hangaishi A, Kurokawa M, Chiba S, Bailey DK, Kennedy GC and Ogawa $\mathrm{S}$ : A robust algorithm for copy number detection using highdensity oligonucleotide single nucleotide polymorphism genotyping arrays. Cancer Res 65(14): 6071-6079, 2005.

12 Nagoshi H, Taki T, Hanamura I, Nitta M, Otsuki T, Nishida K, Okuda K, Sakamoto N, Kobayashi S, Yamamoto-Sugitani M, Tsutsumi Y, Kobayashi T, Matsumoto Y, Horiike S, Kuroda J and Taniwaki M: Frequent PVT1 rearrangement and novel chimeric genes PVT1-NBEA and PVT1-WWOX occur in multiple myeloma with 8q24 abnormality. Cancer Res 72(19): 4954-4962, 2012.

13 Oliver M, Hollstein M and Hainaut P: TP53 Mutations in Human Cancers: Origins, Consequences, and Clinical Use. Cold Spring Harb Perspect Biol 2(1): a001008, 2010. 
14 Nagoshi H, Taki T, Chinen Y, Tatekawa S, Tsukamoto T, Maegawa S, Yamamoto-Sugitani M, Tsutsumi Y, Kobayashi T, Matsumoto Y, Horiike S, Okuno Y, Fujiwara S, Hata H, Kuroda $\mathrm{J}$ and Taniwaki M: Transcriptional dysregulation of the deleted in colorectal carcinoma gene in multiple myeloma and monoclonal gammopathy of undetermined significance. Genes Chromosomes Cancer 54(12): 788-795, 2015.

15 Rummel MJ, Al-Batran SE, Kim SZ, Welslau M, Hecker R, Kofahl-Krause D, Josten KM, Dürk H, Rost A, Neise M, von Grünhagen U, Chow KU, Hansmann ML, Hoelzer D and Mitrou PS: Bendamustine plus rituximab is effective and has a favorable toxicity profile in the treatment of mantle cell and low-grade nonHodgkin's lymphoma. J Clin Oncol 23(15): 3383-3389, 2005.

16 Robinson KS, Williams ME, van der Jagt RH, Cohen P, Herst JA, Tulpule A, Schwartzberg LS, Lemieux B and Cheson BD: Phase II multicenter study of bendamustine plus rituximab in patients with relapsed indolent B-cell and mantle cell nonHodgkin's lymphoma. J Clin Oncol 26(27): 4473-4479, 1984.

17 Leoni LM, Bailey B, Reifert J, Bendall HH, Zeller RW, Corbeil J, Elliott G and Niemeyer CC: Bendamustine (Treanda) displays a distinct pattern of cytotoxicity and unique mechanistic features compared with other alkylating agents. Clin Cancer Res 14(1): 309-317, 2008.

18 Kalaycio M: Bendamustine: a new look at an old drug. Cancer 115(3): 473-479, 2009.

19 Montillo M, Ricci F, Tedeschi A, Vismara E and Morra E: Bendamustine: new perspective for an old drug in lymphoproliferative disorders. Expert Rev Hematol 3(2): 131-148, 2010.

20 Strumberg D, Harstrick A, Doll K, Hoffmann B and Seeber S: Bendamustine hydrochloride activity against doxorubicin-resistant human breast carcinoma cell lines. Anticancer Drugs 7(4): 415421, 1996.

21 Gaul L, Mandl-Weber S, Baumann P, Emmerich B and Schmidmaier R: Bendamustine induces $\mathrm{G} 2$ cell cycle arrest and apoptosis in myeloma cells: the role of ATM-Chk2-Cdc25A and ATM-p53-p21-pathways. J Cancer Res Clin Oncol 134(2): 245253, 2008.

22 Hagiwara K, Tokunaga T, Iida H and Nagai H: Synergistic cytotoxicity of bendamustine and the BTK inhibitor in a mantle cell lymphoma cell line. Anticancer Res 35(12): 6679-6684, 2015.

23 Rolland D, Raharijaona M, Barbarat A, Houlgatte R and Thieblemont C: Inhibition of GST-pi nuclear transfer increases mantle cell lymphoma sensitivity to cisplatin, cytarabine, gemcitabine, bortezomib and doxorubicin. Anticancer Res 30(10): 3951-3957, 2010.

$24 \mathrm{He}$ S, Liu F, Xie Z, Zu X, Xu W and Jiang Y: P-Glycoprotein/ MDR1 regulates pokemon gene transcription through p53 expression in human breast cancer cells. Int J Mol Sci 11(9): 3309$3051,2010$.
25 Ruefli AA, Tainton KM, Darcy PK, Smyth MJ and Johnstone RW: P-glycoprotein inhibits caspase-8 activation but not formation of the death inducing signal complex (disc) following Fas ligation. Cell Death Differ 9(11): 1266-1272, 2002.

26 Bubencíkova T, Cholujová D, Messingerová L, Mislovicova D, Seres M, Breier A and Sulova Z: Detection of glycomic alterations induced by overexpression of p-glycoprotein on the surfaces of L1210 cells using sialic acid binding lectins. Int J Mol Sci 13(11): 15177-15192, 2012.

27 Breier A, Gibalova L, Seres M, Barancik M and Sulova Z: New insight into p-glycoprotein as a drug target. Anticancer Agents Med Chem 13(1): 159-170, 2013.

28 Bottke D, Koychev D, Busse A, Heufelder K, Wiegel T, Thiel E, Hinkelbein W and Keilholz U: Fractionated irradiation can induce functionally relevant multidrug resistance gene and protein expression in human tumor cell lines. Radiat Res 170(1): 41-48, 2008.

29 Nobili S, Landini I, Giglioni B and Mini E: Pharmacological strategies for overcoming multidrug resistance. Curr Drug Targets 7(7): 861-879, 2006.

30 Kim YK, Song YJ, Seo DW, Kang DW, Lee HY, Rhee DK, Han JW, Ahn CM, Lee S and Kim SN: Reversal of multidrug resistance by 4-chloro-N-(3-((E)-3-(4-hydroxy-3-methoxyphenyl)acryloyl)phenyl)benzamide through the reversible inhibition of P-glycoprotein. Biochem Biophys Res Commun 355(1): 136-142, 2007.

31 Teichert J, Sohr R, Baumann F, Hennig L, Merkle K, Caca K and Preiss R: Synthesis and characterization of some new phase II metabolites of the alkylator bendamustine and their identification in human bile, urine, and plasma from patients with cholangiocarcinoma. Drug Metab Dispos 33(7): 984-992, 2005.

32 Bennaceur-Griscelli A, Bosq J, Koscielny S, Lefrère F, Turhan A, Brousse N, Hermine O and Ribrag V: High level of glutathioneS-transferase pi expression in mantle cell lymphomas. Clin Cancer Res 10(9): 3029-3034, 2004.

33 Bernig T, Ritz S, Brodt G, Volkmer I and Staege MS: Glutathione-S-transferases and Chemotherapy Resistance of Hodgkin's Lymphoma Cell Lines. Anticancer Res 36(8): 3905$3915,2016$.
Received February 19, 2018

Revised March 22, 2018

Accepted March 23, 2018 